\title{
Functional morphology of the brain of the African giant pouched rat (Cricetomys gambianus Waterhouse, 1840)
}

\begin{tabular}{|c|c|}
\hline $\begin{array}{l}\text { Authors: } \\
\text { Chikera S. Ibe } \\
\text { Barth I. Onyea } \\
\text { Joseph O. Ham }\end{array}$ & $\begin{array}{l}\text { husi }^{1} \\
\text { bolu }\end{array}$ \\
\hline \multicolumn{2}{|c|}{$\begin{array}{l}\text { Affiliations: } \\
{ }^{1} \text { Department of Veterinary } \\
\text { Anatomy, Ahmadu Bello } \\
\text { University, Nigeria }\end{array}$} \\
\hline \multicolumn{2}{|c|}{$\begin{array}{l}\text { Correspondence to: } \\
\text { Chikera Ibe }\end{array}$} \\
\hline \multicolumn{2}{|c|}{$\begin{array}{l}\text { Email: } \\
\text { writechikera@yahoo.com }\end{array}$} \\
\hline \multicolumn{2}{|c|}{$\begin{array}{l}\text { Postal address: } \\
\text { Department of Veterinary } \\
\text { Anatomy, Ahmadu Bello } \\
\text { University, Zaria 2222, } \\
\text { Nigeria }\end{array}$} \\
\hline \multicolumn{2}{|c|}{$\begin{array}{l}\text { Dates: } \\
\text { Received: } 12 \text { July } 2013 \\
\text { Accepted: } 02 \text { Sep. } 2013 \\
\text { Published: } 28 \text { Mar. } 2014\end{array}$} \\
\hline \multicolumn{2}{|c|}{$\begin{array}{l}\text { How to cite this article: } \\
\text { Ibe, C.S., Onyeanusi, B.I. } \\
\text { \& Hambolu, J.O., 2014, } \\
\text { 'Functional morphology of } \\
\text { the brain of the African giant } \\
\text { pouched rat (Cricetomys } \\
\text { gambianus Waterhouse, } \\
\text { 1840)', Onderstepoort Journal } \\
\text { of Veterinary Research 81(1), } \\
\text { Art. \#644, } 7 \text { pages. http:// } \\
\text { dx.doi.org/10.4102/ojvr. } \\
\text { v81i1.644 }\end{array}$} \\
\hline \multicolumn{2}{|c|}{$\begin{array}{l}\text { Copyright: } \\
\text { (C) 2014. The Authors. } \\
\text { Licensee: AOSIS } \\
\text { OpenJournals. This wo } \\
\text { is licensed under the } \\
\text { Creative Commons } \\
\text { Attribution License. }\end{array}$} \\
\hline \multicolumn{2}{|l|}{ Read online: } \\
\hline 口ifa & $\begin{array}{l}\text { Scan this QR } \\
\text { code with your } \\
\text { smart phone or } \\
\text { mobile device } \\
\text { to read online. }\end{array}$ \\
\hline
\end{tabular}

A gross morphological study of the brain of the African giant pouched rat (Cricetomys gambianus Waterhouse, 1840) was undertaken in order to document its normal features and assess the structure-function paradigm. The study was conducted by direct observation of 29 adult African giant pouched rats' brains. In the telencephalon, the cerebral cortex was devoid of prominent gyri and sulci, but the large olfactory bulb and tract relaying impulses to the olfactory cortex were very prominent. The large size of the olfactory bulb correlated with the established sharp olfactory acuity of the rodent. In the mesencephalic tectum, the caudal colliculi were bigger than the rostral colliculi, indicating a more acute sense of hearing than sight. In the metencephalon, the cerebellar vermis, the flocculus and the paraflocculus were highly coiled and, thus, well developed. The myelencephalon revealed a better organised ventral surface than dorsal surface; the cuneate fascicle, the intermediate sulcus and the lateral sulcus were not evident on the dorsal surface, but there were clearly visible pyramids and olivary prominence on the ventral surface. In conclusion, the highly coiled cerebellar vermis, flocculus and paraflocculus, as well as the conspicuous pyramids and olivary prominence are indicative of a good motor coordination and balance in the African giant pouched rat.

\section{Introduction}

The brain is the control centre of the vital activities that are necessary for survival. It receives sensory impulses from the sensory organs through the spinal cord and cranial nerves, processes these impulses and initiates motor outputs to effector organs. Thus, the brain is the organ that is specialised in coordinating activities in relation to changes in the internal and external environments.

The adult brain is divided into the forebrain (telencephalon and diencephalon), midbrain (mesencephalon) and hindbrain (metencephalon and myelencephalon). The brain can also be divided into the cerebrum, cerebellum and brainstem. The cerebrum attaches to the brainstem by the cerebral peduncles, while the cerebellum attaches to the brainstem by the cerebellar peduncles. The cerebrum is the main constituent of the telencephalon, while the thalamus, epithalamus, metathalamus and hypothalamus make up the diencephalon (Delahunta \& Glass 2009). The metencephalon is made up of the cerebellum and the pons, also called pons Varolii after Costanzo Varolio (1543-1575), the Italian anatomist who discovered it (Tubbs et al. 2008). The myelencephalon is composed of the medulla oblongata and caudal portion of the fourth ventricle (Darly 1965; Wingerd 1988). The cerebrospinal fluid, which provides mechanical protection and nourishment to the brain, circulates through the two lateral ventricles in the telencephalon, the third ventricle in the diencephalon and the fourth ventricle in the hindbrain.

The macroscopic appearance of the brain differs in mammals, depending on their different adaptations and lifestyles. For example, animals that lack brachiation as a mode of locomotion, such as members of the order Artiodactyla, lack a visible olivary body (Adogwa 1985; Ghaji 1983; Marsden \& Rowland 1965).

The African giant pouched rat (Cricetomys gambianus Waterhouse, 1840) has been successfully used to detect land mines in Mozambique (Mott 2004) and diagnose tuberculosis in Europe (Maggie 2003). It is able to do this because of its high acuity of olfaction, which is a function of the rhinencephalon. Also, the poor sense of sight of the rodent, which is a reason for its nocturnal behaviour, has been attributed to the small rostral colliculi, relative to the caudal colliculi (Ibe et al. 2010). There is lack of information on the functional morphology of the brain of the African giant pouched rat. Therefore, the aim of this research was to study the gross morphology of the brain of the African giant pouched rat and propose some of its morphofunctional paradigms. 


\section{Materials and methods Experimental animals and management}

Twenty-nine captive and clinically healthy adult African giant pouched rats were used for this study. The animals were captured live from the wild in Kaduna State, Nigeria, using locally made traps. The traps were made of galvanised metal and were $1.3 \mathrm{~m} \times 0.3 \mathrm{~m} \times 0.1 \mathrm{~m}$ in dimension. The rats were transported by road in laboratory cages to the animal pen of the Department of Veterinary Anatomy, Ahmadu Bello University, Zaria; they were acclimatised for one month before the commencement of the experiment. During this period, they were physically examined in the cage under careful restraint. Only healthy rats were utilised for this study. The animals were given access to food and drinking water ad libitum throughout the experimental period.

\section{Brain extraction and gross morphological assessment}

The body weight of each rat was obtained using a digital electronic balance (Citizen Scales [1] PVT Ltd., Switzerland), with a sensitivity of $0.01 \mathrm{~g}$. Immediately after chloroform euthanasia in a closed container, physiologic saline solution was used to perfuse the brain through the common carotid artery, in order to flush the brain free of blood. This procedure was immediately followed by perfusion of the brain with $10 \%$ phosphate-buffered formalin. Each skull was exposed after skinning and stripping off all the facial muscles within 30 minutes of euthanasia. Craniotomy, through the calvaria, exposed the dura mater, which was cut with a pair of curved pointed scissors. The falx cerebri and tentorium cerebelli were both pulled from the longitudinal and transverse fissures of the brain, respectively, by gentle traction. The cerebral vein was cut with a pair of sharp scissors. At this stage, the brain (still within the cranium) was fixed in 10\% phosphatebuffered formalin for three days; this was done to facilitate its easy extraction according to the method of Ramaswamy (1978) (using delicate rongeurs, spatulas, forceps and scissors). The extracted brain was then examined and found to be devoid of any macroscopic pathology. The structural characteristics of the different components of the brain were examined with the naked eye. These included their shape, size, surfaces, borders and angles. The presence or absence of sulci, fissures or prominences was also evaluated. Finally, the projections of the different cranial nerves from the myelencephalon were observed with both the naked eye and with the aid of a hand lens. Definitions of gross anatomical structures were based on standard information on rodent anatomy (Parker \& Haswell 1974; Olds \& Olds 1979; Suckow, Weisbroth \& Franklin 2006). Nomina Anatomica Veterinaria (2005) was used for the nomenclature.

\section{Results}

The gross anatomical features observed in the present study were consistent in all brain samples that were dissected.

\section{Telencephalon}

On a dorsal view of the intact brain (Figure 1), the two cerebral hemispheres or neocortex were distinctly divided by a longitudinal fissure and separated from the cerebellum by a transverse fissure. Each neocortex was large, diamondshaped, narrow rostrally and wider caudally. It was devoid of prominent gyri and sulci; however, the bulging of the frontal lobe was evident. The olfactory bulbs were also very prominent and visible from the dorsal view. They were roughly pyramidal in shape.

On a ventral view (Figure 2), the large olfactory bulbs and tracts relaying impulses to the olfactory cortex were evident. The olfactory nerve fibres, which were rostral to the bulbs, could not be accessed due to their position in the cribriform plate of the ethmoid bones. The large size of the olfactory bulbs was of interest, owing to their importance in the sense of smell of the rodent. The olfactory bulbs gave off the medial, lateral and middle olfactory tracts that conveyed sensory impulses to the olfactory cortex (Figure 2: B, C and D). The lateral olfactory tracts continued into their ipsilateral pyriform lobes (Figure 2: I).

\section{Diencephalon}

On a dorsal view of the brainstem, the medial surface of the thalamus formed the lateral boundary of the third ventricle

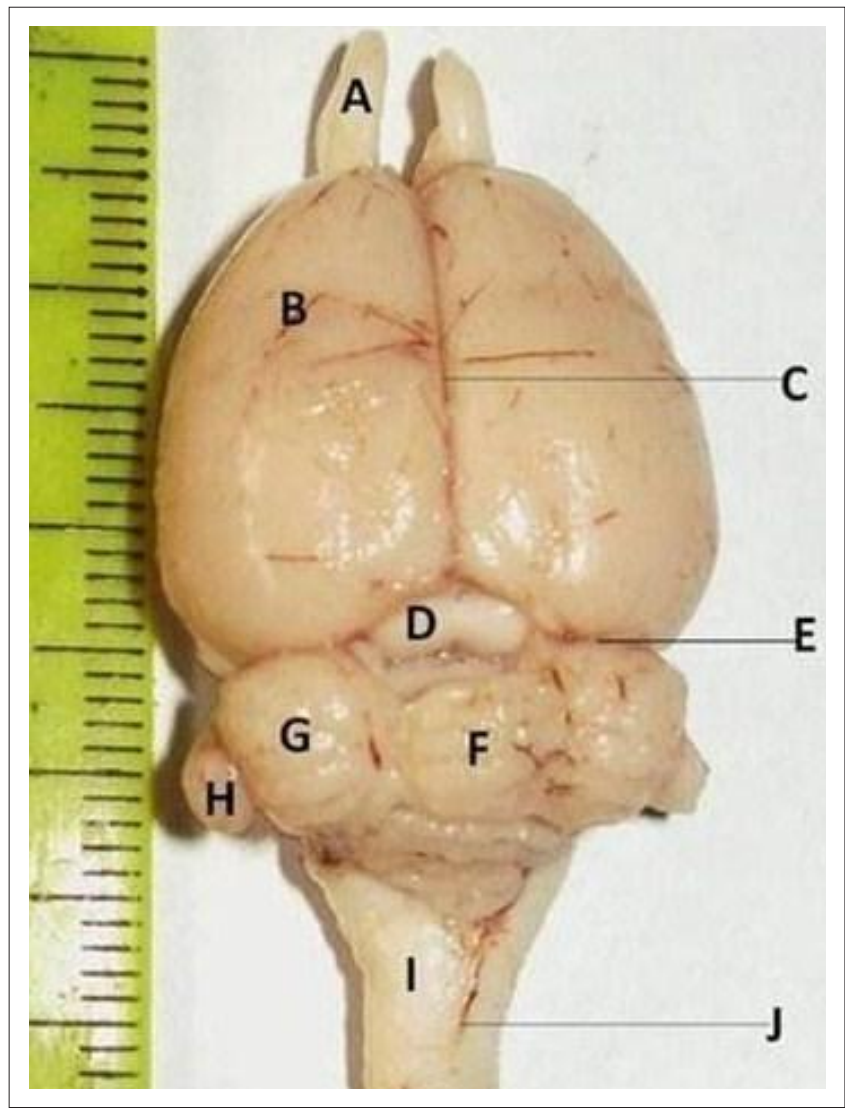

A, Olfactory bulb; B, Cerebral cortex; C, Cerebral longitudinal fissure; D, Caudal colliculus; E, Cerebral transverse fissure; F, Vermis; G, Flocculus; H, Paraflocculus; I, Medulla oblongata; J, Dorsal medial sulcus.

FIGURE 1: Dorsal view of the brain of the adult African giant pouched rat. 
(Figure 3: B and C). Caudal to the thalamus and lateral to the rostral colliculus was a small protuberance, the lateral geniculate body. The caudal border of the thalamus was wider than the rostral border, thus overlapping the rostral colliculus and occluding the lateral geniculate body from the dorsal view of the brainstem (Figure 3 ). The rostral colliculus was continuous with the lateral geniculate body through its brachium. Below the lateral geniculate body and lateral to the caudal colliculus was the medial geniculate body (Figure 3: F). The caudal colliculus was also continuous bilaterally with the medial geniculate body through its brachium. However, the brachia were not clearly visible. The lateral geniculate body was apparently more distinct than the medial geniculate body. The geniculate bodies made up the metathalamus of the diencephalon. The pineal gland (part of the epithalamus) was very small in the African giant pouched rat.

Ventrally (Figure 2), the paired optic nerves (cranial nerve [CN] II) united at the optic chiasma and gave off optic tracts that ran on the rostral boarder of the tuber cinerium. They were the fourth largest diameter cranial nerve after the trigeminal nerve $(\mathrm{CN} \mathrm{V})$, facial nerve (CN VII) and olfactory nerve (CN I) in all of the dissected animals. The oculomotor nerve (CN III) and trochlear nerve (CN IV) were lost during

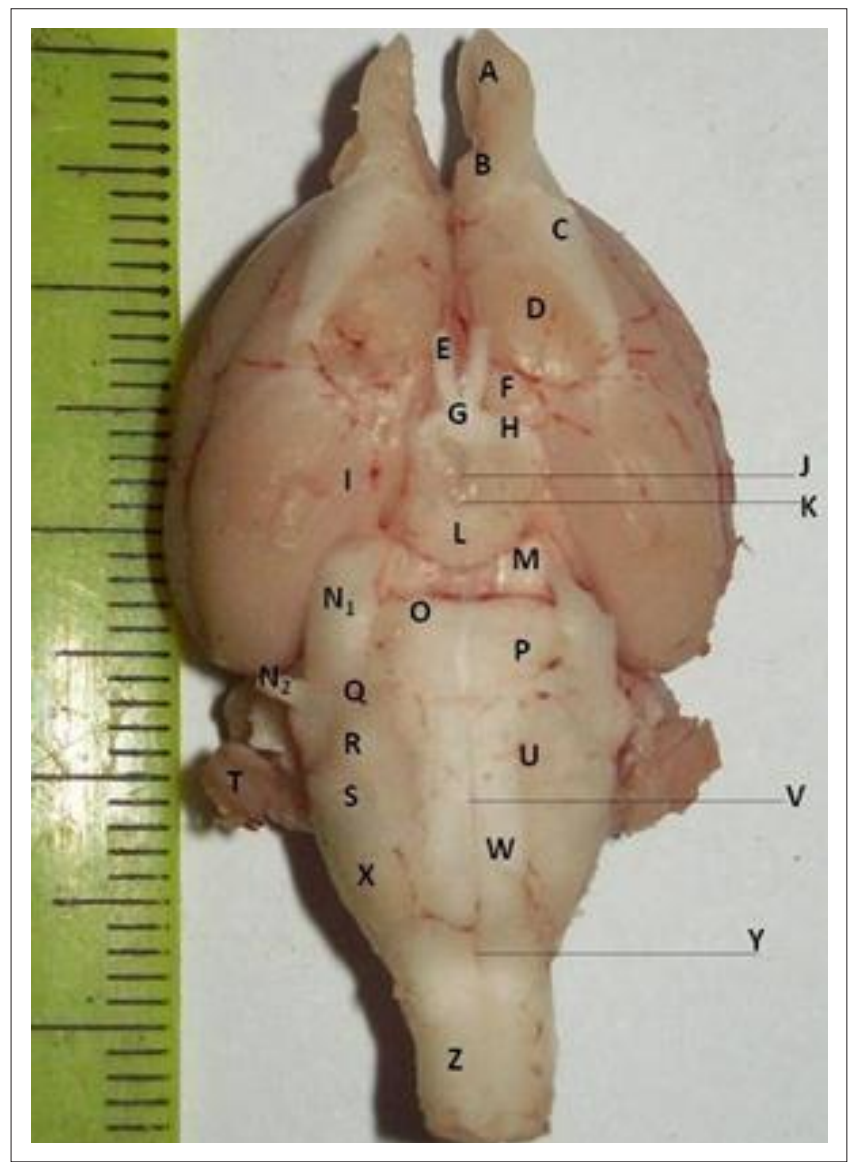

A, Olfactory bulb; B, Medial olfactory tracts; C, Lateral olfactory tracts; D, Middle olfactory tracts; E, Optic nerve (CN II); F, Olfactory tubercle; G, Optic chiasma; H, Optic tracts; I, Piriform lobes; J, Infundibulum; K, Cinerium tuber; L, Mamillary bodies; $\mathrm{M}$, Cerebral crus; $\mathrm{N}_{1}$, Trigeminal nerves (CN V); $\mathrm{N}_{2}$, Vestibulocochlear nerves (CN VIII); O, Pons; P, Trapezoid body; Q, Pre-olivary sulcus (CN IX-XI); R, Olivary body; S, Post-olivary sulcus (CN XII); T, Paraflocculus; U, Lateral ventral sulcus; V, Ventral medial fissure; W, Pyramid; $X$, Medulla oblongata; $Y$, Pyramidia decussation; Z, Spinal medulla.

FIGURE 2: Ventral view of the brain of the African giant pouched rat. dissection due to their minute size. The mamillary bodies (Figure 2: L) were relatively large, interposed between the pyriform lobes laterally, related to the optic chiasma rostrally, and separated from the pons by the cerebral peduncle and the mesencephalon in its caudal portion.

\section{Mesencephalon}

Dorsally, the mesencephalon separated the third ventricle from the fourth ventricle (Figure 3), while ventrally it extended from the caudal portion of the mamillary body to the most rostral part of the pons (Figure 2). The mesencephalic aqueduct passed through the midbrain and connected the third ventricle cranially to the fourth ventricle caudally. The mesencephalic tectum formed the roof of the mesencephalon. It was composed of the corpora quadrigemina. Rostral to the corpora quadrigemina was the third ventricle and caudal to the corpora quadrigemina was the fourth ventricle (Figure 3). The eminence of the corpora quadrigemina was composed of a pair

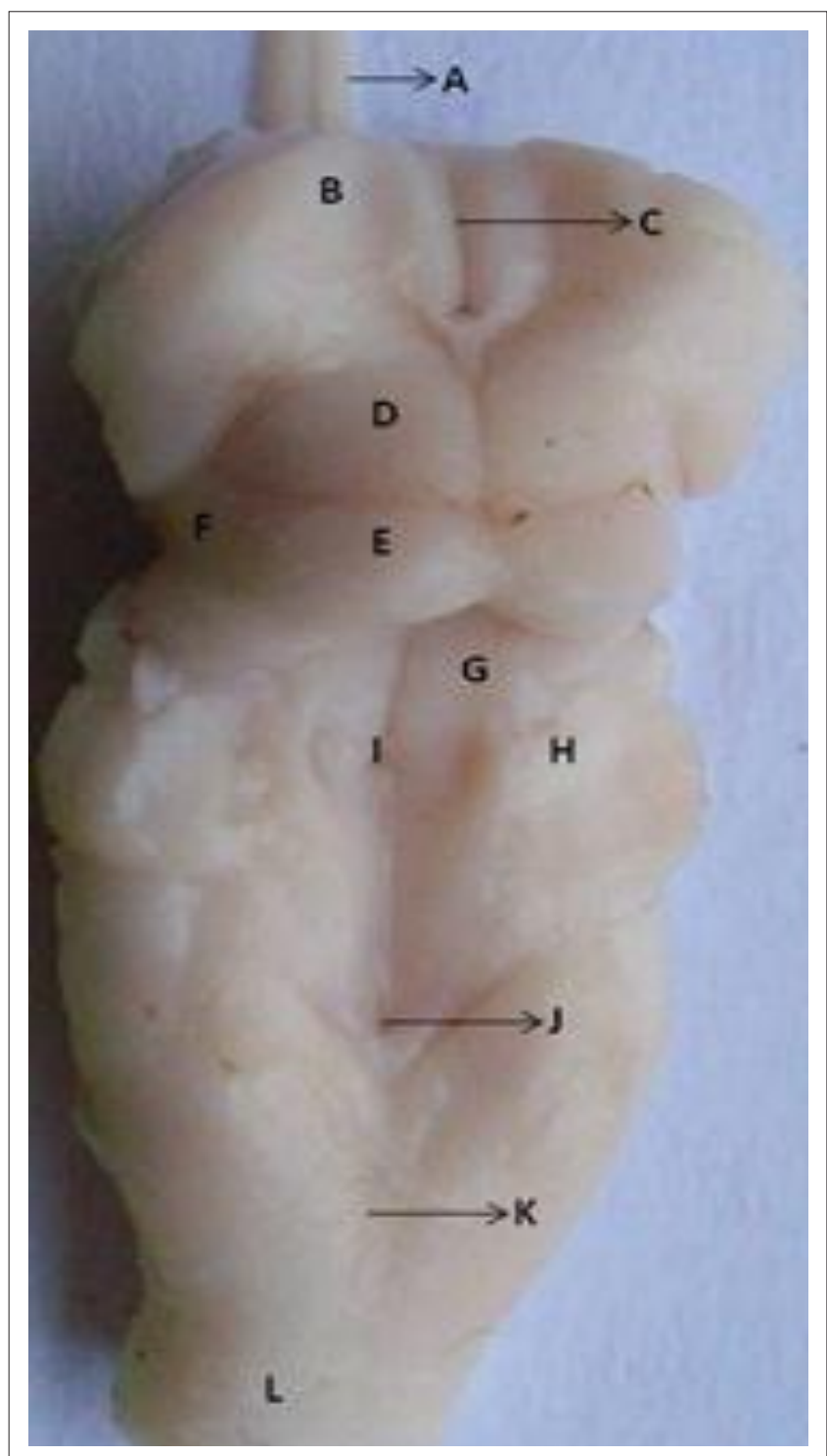

A, Optic nerve; B, Thalamus; C, Ventriculus tertius; D, Rostral colliculus; E, Caudal colliculus; F, Medial geniculate body; G, Sulcus limitans; H, Medial cerebral Peduncle; I, Rhomboid fossa; J, Medial sulcus; K, Obex; L, Medulla oblongata.

FIGURE 3: Dorsal view of the brainstem of the African giant pouched rat. 
of rostral colliculi and a pair of caudal colliculi (Figure 3: D and E); a transverse fissure separated both. A longitudinal fissure separated each pair of colliculi. The caudal colliculi were oval in shape, while the rostral colliculi were conical. The caudal colliculi were visibly bigger than the rostral colliculi. On the dorsal view of the intact brain, the caudal colliculi were visible through the transverse fissure (Figure 1: D), which was suggestive of their large size relative to the rostral colliculi.

On sagittal view of the brain (Figure 4) the corpus callosum was well developed, broad and sickle-shaped; it was well delineated into the rostrum, genu, truncus and splenium (Figure 4: D, E, F and G). Also, on this view the rostral colliculi and the rostral part of the caudal colliculi were covered by the cerebral cortex, while the transverse cerebral fissure exposed the caudal half of the caudal colliculi. The commissural fibres of the colliculi were not prominent. This view also showed that the rostral colliculi were smaller than the caudal colliculi (Figure 4: J and K). The mesencephalic tegmentum formed the floor of the mesencephalon (Figure 4: L), while the substantial nigra separated the tectum from the tegmentum.

\section{Metencephalon}

On dorsal view of the intact brain (Figure 1), the cerebellum was very distinct and secondary to the cerebrum in size. The cerebellar hemisphere was highly coiled with a distinct unpaired vermis; the paired flocculus, with its lateral accessory part, the paraflocculus, was also paired (Figure 1: H, G and F). This depicted a well-developed cerebellum. The arbor vitae, which constitutes the white matter component of the cerebellar folia, was distinct (Figure 4: a). The vermis was the largest cerebellar lobe, while the flocculus was larger than the paraflocculus. On this view, the cerebellum completely covered the fourth ventricle, forming the roof of the ventricle, thus rendering it invisible. On a sagittal view of the vermis (Figure 4: T), the rostral lobe was divided by fissures into the following lobules: the lingula (Figure 4: c), the central lobule (Figure 4: d) and the culmen (Figure 4: e). The caudal lobe was divided into the following lobules: declive (Figure 4: g); fused folium and tuber (Figure 4: h); fused pyramis and uvula (Figure 4: j); and the nodulus (Figure 4: b), which was separated from the uvula by the uvulonodularis fissure (Figure 4: R).

The pons of the African giant pouched rat was almost inconspicuous. However, it was observed as a transverse band of nerve fibre caudal to the cerebral crus and rostral to the trapezoid body on the ventral surface of the brain (Figure 2: $\mathrm{O}$ ). Caudally, it formed part of the rostral part of the rhomboid fossa. It was pre-trigeminal, as the large trigeminal nerve emerged from the brainstem caudolateral to the pons and rostral to the trapezoid body (Figure 2: $\mathrm{N}_{1}, \mathrm{O}$ and $\mathrm{P}$ )

\section{Myelencephalon}

The myelencephalon extended from the point of the nuchal flexure, which is caudal to the pyramidal decussation, to the pontomedullary junction. These were the convenient landmarks for isolating the myelencephalon. The central canal of the spinal cord continued rostrally to the medulla

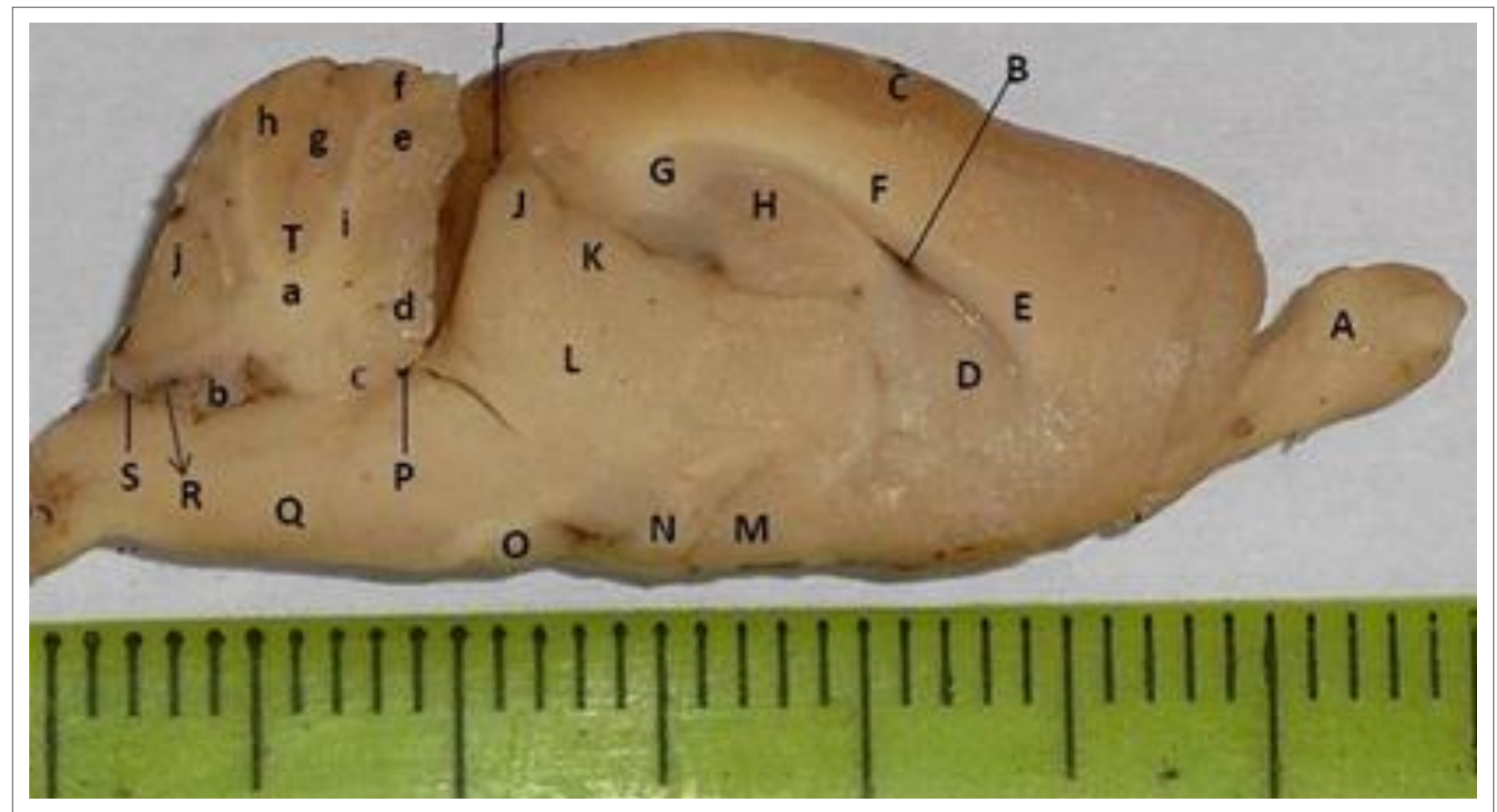

A, Olfactory bulbs; B, Lateral ventricle; C, Cerebral cortex; D, Corpus callosum (Rostral); E, Corpus callosum (Genu); F, Corpus callosum (Truncus); G, Corpus callosum (Splenium); H, Inter-thalamic adhesion; I, Transverse cerebral fissure; J, Caudal colliculus; K, Rostral colliculus; L, Mesencephalic tegmentum; M, Optic chiasma; N, Pituitary gland; O, Pons; P, Rostral medullary velum; Q, Medulla oblongata; R, Uvulonodulary fissure; S, Caudal medullary velum; T, Vermis; a, Arbor vitae; b, Nodulus; c, Lingula; d, Central lobe; e, Culmen; f, Vallecula cerebella; $g$, Declive; h, Tuber vermis and Folium vermis; I, Cerebellar medulla; j, Uvula (Vermis) and Pyramis (Vermis).

FIGURE 4: Mid-sagittal view of the brain of the African giant pouched rat. 
oblongata. In the upper half of the myelencephalon, it continued dorsally as the cavity of the fourth ventricle. The myelencephalon was conical in shape, its broad extremity being directed rostrally; it was compressed dorsoventrally. Its ventral surface rested on the basilar portion of the occipital bone, while the dorsal surface was partly covered by the cerebellum. It created an impression on the occipital bone.

On dorsal view, the most medial part of the myelencephalon was the dorsal median sulcus, which was faintly visible (Figure 1: J). The dorsal median sulcus continued on the floor of the fourth ventricle, where it was more visible than in the closed part of the myelencephalon. It divided the myelencephalon into symmetrical halves. In the medulla oblongata, on either side of the dorsal median sulcus the gracile fasciculus was faintly visible. The cuneate fasciculus, the dorsal intermediate sulcus, the lateral funiculus and the dorsal lateral sulcus were not macroscopically visible. Rostral to the gracile fasciculus and directly caudal to the obex was the tubercle of gracile nucleus. This tubercle contributed to the caudal border of the floor of the fourth ventricle. The tubercle of the cuneate nucleus was not prominent. The obex (Figure 3: K) marked the end of the fourth ventricle and the beginning of the central canal. Rostral to the obex was the rhomboid fossa, which was separated into two equal halves by the dorsal median sulcus. The rhomboid fossa, which formed the floor of the fourth ventricle, tapered into the calamus scriptorius rostrally and closed into the central canal at the obex caudally. It was bounded laterally by an inconspicuous sulcus limitans. However, at its greatest width, it extended laterally as the canalis comminicans into the lateral recess. A convex prominence, corresponding to the underlying vestibular nucleus, was evident between the sulcus limitans medially and the medial cerebellar peduncles laterally. The hypoglossal trigone and vagal trigone were not visible.

On ventral view, the most rostral part of the myelencephalon was the prominent trapezoid body (Figure 2: P). The most medial part was the ventral median fissure (Figure 2: V). On either side of the ventral median fissure was the prominent pyramid (Figure 2: W). The olivary prominence was situated lateral to each of the pyramids, from which it was separated by the ventral lateral sulcus. The deep ventral lateral sulcus was indicative of the prominent pyramids. The olivary prominence was also distinct (Figure 2: R). Between the rostral end of this prominence and the trapezoid body, there was a slight depression, corresponding to the preolivary sulcus. Caudal to the olivary prominence was the post-olivary sulcus. The rootlets of nerves that emerged from these sulci were lost during dissection, thus, could not be evaluated. Rostrally, the pyramids ended at the pontomedullary junction. The basal pons served as the landmark for identifying the pontomedullary junction. The transverse bundle of fibres that made up the trapezoid body was parallel to the pons and was immediately caudal to it. Caudally, the medulla oblongata could be differentiated from the spinal cord by the prominent transverse depression caudal to the pyramidal decussation at the level of the foramen magnum.

\section{Ethical considerations}

The procedure for the research project was approved by the Ethical Committee of Ahmadu Bello University, Zaria, Nigeria. The housing and management of the animals were in accordance with that stated in the Guide for the Care and Use of Laboratory Animals, 8th edition, National Research Council, USA, downloaded from the National Academic Press, Washington D.C. (http://www.nap.edu/).

\section{Discussion}

In the present study, apart from the frontal lobe, the cerebral hemisphere in the African giant pouched rat lacked prominent gyri and sulci. The absence of prominent neocortical sulci placed the African giant pouched rat brain in the lissencephalic group. A similar lissencephalic brain has been reported in some sciuromorphs and myomorphs by Pilleri, Gihr and Kraus (1984) and in hystricomorphs by Dozo, Vucetich and Candela (2004). The African giant pouched rat has a large diamond-shaped neocortex, as recorded in the present study. Nzalak et al. (2008) recorded a neocortex ratio (relative neocortex weight) of $66 \%$ in this rodent. This value is within the range of neocortex ratios for primates, as stipulated by Dunbar (1996) who also stated that the neocortex ratio might serve as a measure of cognitive function in animals. This implies that the sense of reasoning and intelligence may be high in the African giant pouched rat, as is found in some primates.

Well-developed olfactory bulbs were observed in the present study; they were visible from the dorsal view of the intact brain, although they are structures located on the ventral surface of the brain. The conspicuous olfactory bulbs observed in the present study agreed with the findings of Nzalak et al. (2008). In some mammals, such as elephants (Shoshani, Kupsky \& Marchant 2006), the olfactory bulbs are small and therefore not visible from the dorsal view of intact brain; while in other mammals, such as whales (Marino et al. 2003), olfactory structures are absent. According to the morphometric analysis reported by Nzalak et al. (2008), the olfactory bulbs of the adult African giant pouched rat are longer than those of the adult African grasscutter (Thryonomys swinderianus). Rombaux et al. (2006) emphasised that the size of the olfactory bulb is a good indication of the acuity of olfaction in an individual. This may be one of the reasons why the African giant pouched rat is used to detect landmines and diagnose tuberculosis by odour perception. The rodent may also rely heavily on its olfaction, since the sense of sight is poorly developed (Morris 1963; Ajayi 1975; Smithers 1985; Ibe et al. 2010).

The present study shows that the caudal colliculi are macroscopically bigger than the rostral colliculi in the African giant pouched rat. Ibe et al. (2010) showed that the difference in height as well as in diameter of the colliculi in the African giant pouched rat was very highly significant $(p<0.001)$; the caudal colliculi is wider and higher than the rostral colliculi. 
The rostral colliculi are bigger than the caudal colliculi in the rabbit (Bensley 2009), dog (Meyer 1964), calf (Schmidt et al. 2009), donkey (Oto \& Haziroğlu 2009) and camel (Adogwa 1985; Mensah-Brown \& Garey 2006), while the caudal colliculi are bigger than the rostral colliculi in the pig (Getty 1975) and cetaceans (Marino et al. 2003). McFerland, Morgane and Jacobs (1969) reported that the caudal colliculi are enlarged in species using ecolocation. This implies that the acoustic system of this nocturnal rodent may be more efficient than the visual system.

The present study shows a well-developed vermis in the cerebellum of the African giant pouched rat, which is indicative of good motor coordination and balance. Despite the greater brain weight of the African grasscutter relative to that of the African giant pouched rat, as reported by Nzalak et al. (2008), the cerebellum weighs relatively more in the African giant pouched rat than in the African grasscutter. The authors recorded a relative weight of $14.0 \%$ and $12.5 \%$ in the cerebellum of the African giant pouched rat and African grasscutter, respectively. The authors also reported a relatively higher cerebellar length in the African giant pouched rat (23.0\%) than in the African grasscutter (20.3\%). Thus, the cerebellum of the African giant pouched rat is more developed than that of the African grasscutter, which may confer more-efficient motor coordination and balance in the African giant pouched rat than in the African grasscutter.

The pons in the African giant pouched rat, as observed in the present study, is small. According to Masdern and Rowland (1965), the relative sizes of the pons indicate the functional significance of the cortico-pontine and striatopontine pathways. They also reported that the pons increases in size and complexity, reaching maximum development in primates. This progressive phylogenetic increase explains the inconspicuous pons observed in the study, as rodents are among the first orders of the eutherian mammals (Parker \& Heswell 1974). Masdern and Rowland (1965) reported that the pons is post-trigeminal in monotremes and pretrigeminal in marsupials and most species of lower eutherian orders. This is in agreement with the present study in which the pons of the African giant pouched rat, a lower eutherian order, is pretrigeminal.

The macroscopic appearance of the myelencephalon of the African giant pouched rat in the present study is similar to that of other rodents, but with slight variations. Potter and Brueck (1958) reported that the medulla oblongata in the guinea pig is almost completely covered by the cerebellum. This differs from the result obtained in the present study for the African giant pouched rat in which the cerebellum covered only the rostral part of the myelencephalon. The most striking observation of the myelencephalon in the present study was the absence of distinct cuneate fascicle, dorsal lateral sulcus and dorsal intermediate sulcus on the dorsal surface and the presence of macroscopically visible structures on the ventral surface. Thus, the ventral surface of the myelencephalon may be more developed than the dorsal surface.
In the present study, olivary prominence was observed on the ventral surface of the medulla oblongata in the African giant pouched rat. Marsden and Rowland (1965) reported that olivary prominence is absent in Artiodactyla; but highly developed in primates, especially man. Ghaji (1983) and Adogwa (1985) reported the absence of this prominence in the camel (an Artiodactyl). The presence of the olivary prominence in the present study contributes to the good motor coordination and balance in the African giant pouched rat.

The present study showed that pyramids are macroscopically visible on the ventral medulla oblongata of the African giant pouched rat. Voogd (1998) recorded inconspicuous pyramids in ungulates. The macroscopically visible pyramids are important in fine motor control of the distal limbs (Jennings 2004). Therefore, the ability of the African giant pouched rat to maintain balance only on the hind limbs for a reasonable time, especially when fighting, may be a consequence of the developed pyramids that control motor impulses to the hind limbs.

\section{Conclusion}

The present study has provided some useful information on the macroscopic appearance of the brain of the adult African giant pouched rat in relation to its functions. The study will be of benefit in understanding some of the behaviours of the rodent, which are necessary for its domestication.

\section{Acknowledgement}

The authors wish to acknowledge the leading contributions of Professors S.A. Ojo and J.O. Ayo of the Departments of Veterinary Anatomy and Veterinary Physiology, respectively, of the Ahmadu Bello University, Zaria, Nigeria.

\section{Competing interests}

The authors declare that they have no financial or personal relationships that may have inappropriately influenced them in writing this article.

\section{Authors' contributions}

C.S.I. (Ahmadu Bello University) obtained the animals and conducted the research in the departmental laboratory. B.I.O. (Ahmadu Bello University) supervised the research and edited the manuscript. J.O.H. (Ahmadu Bello University) supervised the research and edited the manuscript.

\section{References}

Adogwa, O.A., 1985, 'Morphologic and cyto-architectural studies on the brainstem of the one-humped camel (Camelus dromedarus)', PhD thesis, Ahmadu Bello University, Zaria.

Ajayi, S.S., 1975, 'Observations on the biology, domestication and reproductive performance of the African Giant rat (Cricetomys gambianus, Waterhouse) in Nigeria', Mammalia 39, 343-364. http://dx.doi.org/10.1515/mamm.1975.39.3.343

Bensley, B.A., 2009, Practical Anatomy of the Rabbit; an Elementary Laboratory Textbook in Mammalian Anatomy, viewed 12 September 2009, from www.biblolife.com/ opensource

Darly, L.W., 1965, Dorland's Illustrated Medical Dictionary, 24th edn., p. 970, W.B. Saunders Company, Philadelphia and London. 
Delahunta, A. \& Glass, E.N., 2009, 'Nonolfactory Rhinencephalon: Limbic Sytem', in A. de Lahunta, Veterinary Neuroanatomy and Clinical Neurology, 3rd edn., pp.
$448-452$, Saunders Elsevier, St. Louis, Missouri. http://dx.doi.org/10.1016/B978448-452, Saunders Elsevier,

Dozo, M.Y., Vucetich, M.G. \& Candela, A.M., 2004, 'Skull anatomy and neuromorphology of Hypsosteiromys, a colhuehuapian erethizontid rodent from Argentina', Journal of Vertebrate Paleontology 24, 228-234. http://dx.doi.org/10.1671/18.1

Dunbar, R., 1996, Grooming, Gossip, and the Evolution of Language, Harvard University Press, Cambridge M.A.

Getty, R., 1975, Sisson and Grossman's Anatomy of the Domestic Animals, 5th edn., W.B. Saunders Company, Philadelphia, London, Toronto.

Ghaji, A., 1983, 'The brain of the one-humped camel (Camelus dromedarius). Morphologic, cytoarchitectural and myeloarchitectural studies', PhD thesis, Ahmadu Bello University, Zaria.

Ibe, C.S., Onyeanusi, B.I., Ayo, J.O., Salami, S.O. \& Ajayi, I.E., 2010, 'Preliminary neuroanatomical study of the visual and auditory senses in the African Giant pouched rat (Cricetomys gambianus, Waterhouse 1840)', 35th Annual Conference of the Nigerian Society for Animal Production (NSAP) proceedings, University of Ibadan, Nigeria, March 14-17, pp. 134-137.

Jennings, D.P., 2004, 'Supraspinal control of posture and movement', in W.O. Reece, (ed.), Dukes' Physiology of Domestic Animals, 1st edn., pp. 904-920, Cornell University Press.

Maggie, M., 2003, Giant Rats to Sniff Out Tuberculosis, viewed 16 December 2008 from http://www.NewScientist.com

Marino, L., Sudheimer, K., Pabst, D.A., McLellan, W.A. \& Johnson, J.I., 2003, 'Magnetic resonance images of the brain of a dwarf sperm whale (Kogia simus)', Journal of Anatomy 203, 57-76. http://dx.doi.org/10.1046/j.1469-7580.2003.00199.x

Marsden, C.D. \& Rowland, R., 1965, 'The mammalian pons, olive and pyramids', Journal of Comparative Neurology 124, 175-188. http://dx.doi.org/10.1002/cne.901240204

McFerland, W.L., Morgane, P.J. \& Jacobs, M.S., 1969, 'Ventricular system of the brain of the dolphin, Tursiops truncatus, with comparative anatomical observations and relations to brain specializations', Journal of Comparative Neurology 135, 275-367. http://dx.doi.org/10.1002/cne.901350304

Mensah-Brown, E.P.K. \& Garey, L.J., 2006, 'The superior colliculus of the camel: A neuronal-specific nuclear protein (NeuN) and neuropeptide study', Journal of Anatomy 208, 239-250. http://dx.doi.org/10.1111/j.1469-7580.2006.00517.x

Meyer, H., 1964, 'The brain', in M.E. Miller, G.C. Christensen \& H.E. Evans (eds.), Anatomy of the Dog, pp. 480-571, W.B. Saunders Company, Philadelphia, London.

Morris, B., 1963, 'Notes on the Giant rat (Cricetomys gambianus) in Nyassaland', African Wild Life 17, 103-107.

Mott, M., 2004, 'Bees, Giant African rats used to sniff landmines', viewed 11 September 2009, from http://news.nationalgeographic.com
Nomina Anatomica Veterinaria, 2005, International Committee on Veterinary Gross Anatomical Nomenclature, 5th edn., Hannover, Columbia.

Nzalak, J.O., Byanet, O., Salami, S.O., Umosen, A.D., Maidawa, S.M., Ali, M.N. et al., 2008, 'Comparative morphometric studies of the cerebellum and forebrain of the African Giant rat (Cricetomys gambianus, Waterhouse) and that of grasscutter (Thryonomys swinderianus)', Journal of Animal and Veterinary Advances 7, 1090-1092.

Olds, R.J. \& Olds, J.R., 1979, A Colour Atlas of the Rat. Dissection Guide, pp. 72-80, Wolfe Medical Publications Ltd., London.

Oto, C. \& Haziroğlu, R.M., 2009, 'Macro-anatomical investigation of encephalon in donkey', Ankara Üniversitesi Veteriner Fakültesi Dergisi 56, 159-164.

Parker, T.J. \& Haswell, W.A., 1974, A Textbook of Zoology. Vertebrates, vol. 2, pp. 116-135, The Macmillan Press Ltd., London and Basingstoke, Great Britain.

Pilleri, G., Gihr, M. \& Kraus, C., 1984, 'Cephalization in rodents with particular reference to the Canadian beaver (Castor canadensis)', in G. Pilleri (ed.), Investigations on Beavers' Institute of Brain Anatomy, pp. 11-102, University of Berne.

Potter, G.E. \& Brueck, W.L., 1958, 'Nervous system of guinea pig (Cavia porcellus)', Bios 29, 185-196.

Ramaswamy, S., 1978, 'Removal of the brain - A new procedure', Italian Journal of Anatomy and Embryology 82, 105-110.

Rombaux, P., Mouraux, A., Bertrand, B., Nicolas, G., Duprez, T. \& Hummel, T., 2006, 'Olfactory function and olfactory bulb volume in patients with postinfectious olfactory loss', Laryngoscope 116, 436-439. http://dx.doi.org/10.1097/01.MLG. 0000195291.36641.1E

Schmidt, M.J., Pilatus, U., Wigger, A., Kramer, M. \& Oelschlager, H.A., 2009, 'Neuroanatomy of the calf brain as revealed by high-resolution magnetic resonance imaging', Journal of Morphology 270, 745-758. http://dx.doi.org/10.1002/jmor.10717

Shoshani, J., Kupsky, W.J. \& Marchant, G.H., 2006, 'Elephant brain: Part I: Gross morphology, functions, comparative anatomy, and evolution', Brain Research Bulletin 70, 124-157. http://dx.doi.org/10.1016/j.brainresbull.2006.03.016

Smithers, R.H.N., 1985, 'The mammals of the southern African subregion', Quarterly Review of Biology 60, 362. http://dx.doi.org/10.1086/414487

Suckow, M.A., Weisbroth, S.H. \& Franklin, C.L., 2006, The Laboratory Rat, pp. 230-439, Elsevier Academic Press, Oxford.

Tubbs, R.S., Loukas, M., Shoja, M.M., Apaydin, N., Ardalan, M.R., Shokouhi, G. et al ., 2008, 'Costanzo Varolio (Constantius Varolius 1543-1575) and the pons Varolli', Neurosurgery 62, 734-737. http://dx.doi.org/10.1227/01.neu.0000317323.63859.2a

Voogd, J., 1998, 'Mammals', in R. Nieuwenhuys, P.A.M. Van Dongen, H.J.N. Donkelaar \& C. Nicholson (eds.), The Central Nervouse System of Vertebrates, Springer Science Online Textbook, viewed 30 June 2009, from http://www.springer.com

Wingerd, B.D., 1988, Rat Dissection Manual, Johns Hopkins University Press, Baltimore. 